\title{
Entrepreneurial ecosystems: a dynamic lifecycle model
}

\author{
Uwe Cantner • James A. Cunningham • \\ Erik E. Lehmann • Matthias Menter (D)
}

Accepted: 8 January 2020 / Published online: 1 February 2020

(C) The Author(s) 2020

\begin{abstract}
The concept of entrepreneurial ecosystems has been used as a framework to explain entrepreneurial activities within regions and industrial sectors. Despite the usefulness of this approach, the concept is undertheorized, especially with regard to the evolution of entrepreneurial ecosystems. The current literature is lacking a theoretical foundation that addresses the development and change of entrepreneurial ecosystems over time and does not consider the inherent dynamics of entrepreneurial ecosystems that lead to their birth, growth, maturity, decline, and re-emergence. Taking an industry lifecycle perspective, this paper addresses this research gap by elaborating a dynamic entrepreneurial ecosystem lifecycle model. We propose that an ecosystem transitions from an entrepreneurial ecosystem, with a focus on new firm creation, towards a business ecosystem, with a core focus on the internal commercialization of knowledge, i.e., intrapreneurial activities, and
\end{abstract}

U. Cantner $(\bowtie) \cdot$ M. Menter

Friedrich Schiller University Jena, Jena, Germany

e-mail: uwe.cantner@uni-jena.de

M. Menter

e-mail: matthias.menter@uni-jena.de

J. A. Cunningham

Northumbria University, Newcastle, UK

e-mail: james.cunningham@northumbria.ac.uk

E. E. Lehmann

University of Augsburg, Augsburg, Germany

e-mail: erik.lehmann@wiwi.uni-augsburg.de vice versa. Our dynamic model thus captures the oscillation that occurs among entrepreneurs and intrapreneurs through the different phases of an ecosystem's lifecycle. Our dynamic lifecycle model may thus serve as a starting point for future empirical studies focusing on ecosystems and provide the basis for a further understanding of the interrelatedness between and coexistence of new and incumbent firms.

Keywords Entrepreneurial ecosystems . Entrepreneurship · Intrapreneurship · Lifecycles · Dynamism · Transition

JEL classifications $\mathrm{O} 31 \cdot \mathrm{O} 32 \cdot \mathrm{O} 33 \cdot \mathrm{L} 26$

\section{Introduction}

Local production matters. One of the first scholars pointing out the importance of localized production was Alfred Marshall (1920) in his pioneering masterwork "Principles of Economics," where he explores how ideas come to be "in the air." Marshall identifies three sources of agglomeration causes bestowing entrepreneurial opportunities, namely labor market pooling, nonpecuniary economics, and knowledge externalities (Audretsch et al., 2006: 84). Since then, economists have begun studying production, innovation, and new firm creation beyond the national or market economy

\footnotetext{
1 "The mysteries of trade become no mysteries; but they are as it were in the air, and children learn many of them unconsciously" (Marshall, 1920: 225).
} 
level on a decentralized and geographic level, trying to explore how and why such agglomeration effects emerge and evolve over time. In particular, the "why" question has been discussed intensively in the literature (see Audretsch, 1998; Ellison \& Glaeser, 1999; Ciccone, 2002): the agglomeration effects identified by Marshall generate positive externalities, and these externalities are locally bounded. In the past decades, a fruitful and promising literature has emerged, analyzing agglomeration effects on a subnational level, where production is locally "clustered." This strand of literature has primarily focused on the evolvement of local clusters where the clustering or agglomeration is driven by either economies of scale (homogenous clusters) or economies of scope (heterogeneous clusters).

How can these insights be transferred to ecosystems? Also in ecosystems, agents compete for scarce resources, but in a cooperative way. The equilibrium is characterized by the complementarities and substitutional interrelations among the economic agents - and will be distorted when only one economic agent survives. Among the various definitions of ecosystems, based on Tansley (1935), Acs et al. (2017a: 2) describe ecosystems as follows: "In its most abstract sense, an ecosystem ("ecological system") is a biotic community, its physical environment, and all the interactions possible in the complex of living and nonliving components." It is one characteristic of an ecosystem that a creature/ agent cannot survive without the others. The suppression of one creature/agent will inevitably lead to a welfare loss of all creatures/agents in the ecosystem if not destroy the entire ecosystem. It is the interrelation of creatures/agents within their nonliving environment which generates a value for all creatures/agents, enabling them to survive, i.e., to reproduce themselves/ progress.

Entrepreneurship (i.e., the exploitation of previously non-commercialized knowledge and ideas) constitutes an essential determinant in the emergence and persistence of an ecosystem, or a regional economic system in general (Liguori et al., 2019). Like Auerswald and Dani (2017), we argue that an entrepreneurial ecosystem and a business ecosystem are subsets and nested within a broader regional economic system. When most of the relevant ideas are commercialized outside established firms by new venture creation, then entrepreneurship is the primary function activity within a regional ecosystem. Then, the entrepreneurial ecosystem should be at the center of interest. Otherwise, if the ideas are commercialized in large parts within established firms, intrapreneurship is the primary function activity in commercializing new ideas and the business ecosystem dominates the regional economic ecosystem. We argue that entrepreneurial ecosystems and business ecosystems are two subsets of a regional economic ecosystem, linked together by whether the exploitation and commercialization of ideas are rather complements or substitutes to existing firm assets.

A pivotal aspect that links entrepreneurial ecosystems with business ecosystems is human capital (Audretsch \& Link, 2019). Knowledge is partly embodied in employees, which makes labor mobility (i.e., the flow of human capital) relevant (Braunerhjelm et al., 2018). Individuals may absorb knowledge and skills from established firms and decide to create a new venture to exploit their ideas. In addition, established firms may favor spin-offs of "intrapreneurial" teams leading to a win-win situation for both, the incumbent firm and the now "entrepreneurial" team (Fabel, 2004). New venture creation and spin-offs reflect labor mobility within a regional economic ecosystem. Hence, an essential characteristic of a vibrant regional economic system is the flow of labor from incumbent firms towards entrepreneurial firms and vice versa. In order to pursue their "corporate entrepreneurship" strategy (see Ireland et al., 2009), incumbent firms strongly depend on absorbing and exploiting new technologies and innovations. Thus, with respect to the proposed specialization among technology-based start-ups and technology-seeking incumbent firms in the market for innovation, incumbent firms enjoy competitive advantages in the commercial exploitation of innovations, while start-up firms enjoy advantages in their exploration (Lehmann \& Schwerdtfeger, 2016; Henkel et al., 2015).

The extant literature on entrepreneurial ecosystems has attempted to account for these inherent mechanisms by investigating their governance configurations (Colombelli et al., 2019; Colombo et al., 2019; Cumming et al., 2019; Cunningham et al., 2019b), their resilience (Roundy et al., 2017), and their evolutionary dynamics (Mack \& Mayer, 2016; Brown \& Mason, 2017; Auerswald \& Dani, 2017). Despite the usefulness of existing frameworks, the current literature is lacking a clear theoretical foundation for the emergence, development, and change of entrepreneurial ecosystems over time, especially with regard to the transition from an entrepreneurial ecosystem towards a business ecosystem and vice versa. A theoretical foundation is yet 
necessary to create a common understanding among scholars, hence allow for cumulativeness in research. Based on our conceptual framework, we elaborate the dynamic nature of entrepreneurial ecosystems and capture the oscillation that occurs among entrepreneurs (new firms) and intrapreneurs (incumbent firms) through the different phases of an ecosystem's lifecycle. We thereby present a dynamic model of ecosystems based on the lifecycle model as introduced by Vernon (1966) and extended for clusters and regions by Klepper (1997). We propose that an ecosystem transitions from an entrepreneurial ecosystem, with a focus on new firm creation, towards a business ecosystem with a core focus on the internal commercialization of knowledge, i.e., intrapreneurial activities, and vice versa. Our lifecycle model thus considers the inherent dynamics of entrepreneurial ecosystems that lead to their birth, growth, maturity, decline, and re-emergence and may serve as a starting point for future empirical studies focusing on ecosystems and provide the basis for a further understanding of the interrelatedness between and coexistence of new and incumbent firms.

The remainder of this paper is structured as follows. Section 2 provides an overview of existing definitions of entrepreneurial ecosystems and highlights that despite the usefulness of this approach, the concept is undertheorized, especially with regard to the evolution of entrepreneurial ecosystems. The subsequent Section 3 focuses on the emergence and the dynamic nature of entrepreneurial ecosystems. Section 4 presents our dynamic lifecycle model of an entrepreneurial ecosystem. A final section concludes our paper.

\section{Literature review}

\subsection{Defining entrepreneurial ecosystems}

As mentioned in the introduction, there has been a growing research focus on entrepreneurial ecosystems as a subset in analyzing geographically bounded agglomeration effects (see Audretsch et al., 2019b). The concept of entrepreneurial ecosystems has been increasingly used by policy makers in their analysis of policy issues with respect to entrepreneurship and economic development. The definition of what an entrepreneurial ecosystem constitutes is open to different interpretations and its origins have often been traced back to ecological systems (Acs et al., 2017a). In a recent review of previous studies of entrepreneurial ecosystems, Tsujimoto et al. (2018) identifies and categorizes four perspectives, the industrial ecological perspective, the business ecosystem perspective, the platform management perspective, and the multi-actor network perspective, whereas Scaringella and Radziwon (2018: 62) for their systematic review of ecosystems use a taxonomy of business, innovation, entrepreneurial, and knowledge ecosystems. Spigel and Harrison (2018) take a processbased view of ecosystems and identify four types of ecosystems - strong, arid, irrigated, and weak-by characterizing and evaluating the respective network strengths and available resources. Spigel (2017: 50) defines entrepreneurial ecosystems as a "combination of social, political and cultural elements within a region that support the development and growth of innovative startups and encourage nascent entrepreneurs and other actors to take the risks of starting, funding, and otherwise assisting high-risk ventures." This individual interaction focus with institutional actors is further elaborated by Acs et al. (2014: 479) in their definition. Based on their study of entrepreneurial variations in 70 European cities, Audretsch and Belitski (2017: 1045) define efficient entrepreneurial ecosystems as "a complex system of interactions between agents within various socioeconomic, institutional and informational contexts which generate more new businesses and growth." Mason and Brown (2014: 5) in their synthesized definition of entrepreneurial ecosystems from the literature emphasize the interactions between actors, institutions, and entrepreneurial processes that are centered on a local environment. Furthermore, they posit that place-based assets, entrepreneurial recycling, culture, finance, and service providers, are some factors that distinguish entrepreneurial ecosystems.

Policy, markets, finance, culture, supports, and human capital are core domains of entrepreneurial ecosystems (Isenberg, 2011; Liguori et al., 2019) and stand-up; start-up and scale-up are structural aspects of entrepreneurial ecosystems (see Autio et al., 2018). Spigel (2017) argues, based on Canadian case studies, that entrepreneurial ecosystems consist of material, cultural, and social attributes. Using the Netherlands as a case study, Stam (2014) develops a model of entrepreneurial ecosystems which consists of framework and systemic conditions, outputs, and outcomes. Narratives that are used within and outside entrepreneurial ecosystems can influence the knowledge transfers and culture as well as enable sense making by ecosystem actors 
such as entrepreneurs (Roundy, 2016). Different actors within entrepreneurial ecosystems can play a leading role in influencing their direction and evolution (Kshetri, 2014). This is further reinforced by Thompson et al. (2018), based on studying entrepreneurial ecosystems over 14 years in Seattle, Washington, suggesting that individual actor's activities centered on shared collective value through everyday activities that provide the resources and infrastructure that support entrepreneurship. This study illustrates the bottom-up approach to ecosystem development.

Some of the definitions and studies of entrepreneurial ecosystems have taken an evolutionary perspective. Taking an economic geography perspective, Mack and Mayer (2016: 2122) pursue an evolutionary perspective that integrates the core domains as posited by Isenberg (2011) and outline how they evolve through the stages of birth, growth, sustainment, and decline. Evolutionary biology and ecological perspectives form the basis and strategies to build effective ecosystems (see Auerswald, 2015). Studying a cluster of biotechnology-related entrepreneurship, Auerswald and Dani (2017) propose an empirical framework which assesses the trajectories of regional entrepreneurial ecosystems. Using a case study of Scottish entrepreneurial ecosystems, Autio and Levie (2017) use ecological economics to create a theoretical framework for entrepreneurial ecosystem management. Moreover, Mason and Brown (2014) also take an evolutionary model that has a regional focus to outline the different steps and activities of entrepreneurial ecosystems. In summing up the state-of-the-art of entrepreneurial ecosystem research, Brown and Mason (2017: 15) state that entrepreneurial ecosystems "appear to be somewhat under-socialised, lacking a time dimension and fail to incorporate the full complexities of the sociospatial context mediating entrepreneurship." The purpose of our paper is to address this research gap by elaborating a dynamic entrepreneurial ecosystem lifecycle model, describing the evolution of such ecosystems over time, and taking into consideration the oscillation that occurs among entrepreneurs and intrapreneurs. We further deal with some of the criticisms of entrepreneurial ecosystems related to our research focus that are outlined in the subsequent section.

\subsection{Some criticisms of entrepreneurial ecosystems}

There have been some criticisms of entrepreneurial ecosystems (see Borissenko \& Boschma, 2016; Oh et al.,
2016) such as the lack of a strong theoretical foundation, governance structures, and how individual factors contribute to the activities of entrepreneurial ecosystems (see Spigel, 2017: 143). Stam's (2015: 1764) criticism focuses on the tautological nature of entrepreneurial ecosystems, as well as the missing explanation of cause and effect of factors and level of analysis (see also Colombo et al., 2019). Moreover, Alvedalen and Boschma (2017) outline several criticisms of entrepreneurial ecosystems including the lack of frameworks distinguishing cause and effect, individual factor connectedness within entrepreneurial systems, individual institutional impact, entrepreneurial ecosystem performance, and studies having a sole focus on single settings.

A major criticism of entrepreneurial ecosystems is how to measure them and what factors to include. There have been some attempts to develop measurement criteria (see Acs et al., 2018; Bruns et al., 2017). For example, Stangler and Bell-Masterson (2015: 2) suggest density, fluidity, connectivity, and diversity as categories along with potential data sources to measure entrepreneurial ecosystems. Autio et al. (2018) call for novel approaches to stimulate entrepreneurial ecosystems that are distinctively different from existing industrial cluster policies, requiring a consideration of economic but also societal outcomes and welfare.

A final core criticism of entrepreneurial ecosystems according to Alvedalen and Boschma (2017) has been on the static nature of approaches that do not consider their evolution. Brown and Mason (2017: 26) argue that researchers in studying entrepreneurial ecosystem need to appreciate more the "complexity of the dynamics" particularly with respect to agency and governances. Entrepreneurial ecosystems research also lacks "historical or contextual sensitivities" (Spigel \& Harrison, 2018). Our dynamic lifecycle model addresses these calls, particularly the static nature of entrepreneurial ecosystems.

\section{The dynamic nature of entrepreneurial ecosystems}

3.1 The mechanisms and boundaries of entrepreneurial ecosystems

The general thinking of ecosystems in the business and management literature is still in terms of systems theory, arguing that ecosystems are aligned to the analogy of 
natural ecosystems "as a community of living organisms in conjunction with the nonliving components of their environment, where the eco part of the word is assumed to be related to the environment and system implies the function as a collection of related parts that function as a unit" (Smith \& Smith, 2015: 19). Scholars are then translating the relevant characteristics into a business and management language. They are replacing living organisms with a set of individuals or stakeholders, like entrepreneurs, venture capitalists, or policy makers interacting together in different ways to pursue an individual and/or common goal. They live or interact in conjunction with nonliving components like universities, incubators, and companies where the "eco" part of the word is assumed to be related to the environment, either local, regional, or national where all parts together function and constitute a unit-the ecosystem (see Ritala \& Almpanopoulou, 2017). The academic literature in this sense treats the "ecosystem" as a metaphor, a new concept, to gain a high attention in the initial state (see Audretsch et al., 2019b; Acs et al. 2017a,b), attracting more and more interest, and to become an academic "hot spot" and then almost burn up. While the metaphor is widely used and, as any innovative idea spreads, so do the misconceptions and mythologies.

The analogy to natural ecosystems lacks in at least three but important differences (see also Kuckertz, 2019). First, natural ecosystems evolve over time and are not created from scratch. The importance in analyzing ecosystems in business and management regarding whether they are artificial or have evolved over time is almost neglected by the literature - leading to a misunderstanding of the metaphor and the implications. The second aspect, related to the first, is the aspect of the boundaries of ecosystems (Colombo et al., 2019). Are ecosystems open or closed, are they geographically bounded or not, are the boundaries real or virtual, are they fix or flexible, static, or dynamic? Since ever, boundaries play an important and crucial role for value creation, performance, and survival: boundaries determine who is in and who is not, who adds and benefits and who does not. ${ }^{2}$ Boundaries define the entry and

\footnotetext{
2 The Epic of Gilgamesh from ancient Mesopotamia (2100 BC), referred to as the earliest surviving great work of literature, describes the building of a wall around Uruk, separating civilization from wilderness. The benefits and value created by division of labor and specialization and the costs of mutual dependence should be protected against the outsiders, the creatures, the wilderness (see Sedlacek, 2011, chapter I.1.).
}

exit conditions and their nature is either natural, like rivers, mountains, or membranes, or artificial like political frontiers, ultimately defining the access to tangible and intangible assets.

The kind of creation, the emergence of an ecosystem, determines the boundaries of an ecosystem impacting the key attribute, the governance structure. In either natural or social ecosystems, value is created by the division of labor and specialization. Such a value creation process leads to mutual independencies at the cost of individual freedom and requests for coordinating and motivating activities - a governance structure (Cunningham et al., 2018). Governance structures coordinate the interactions of individuals, define the boundaries and the entry and exit conditions of the ecosystem, and motivate the individuals to coordinate in an efficient way by rewarding their cooperation with an adequate share from the generated value (Cunningham et al., 2019b; Colombo et al., 2019).

Economic ecosystems in general are complex adaptive systems (see Roundy et al., 2018), where the components, the economic agents have a will of their own, but follow additional rules. Whether the individual economic agent is just maximizing his or her utility or satisficing, economic ecosystems act as if every component is an agent with a will of its own. In doing so, each agent is adjusting to the actions and performance of many other agents. If economic agents react to others, they are reacting to information about what is happening around them, including information about what other agents are doing. As Christian (2018: 78) puts it, "information consists of rules that affects outcomes by limiting possibilities, and that rules determine which changes out of all conceivable options are actually possible at a given time and place, and that makes a difference." An economic ecosystem is a complex adaptive system, a place that consists of different economic agents each following their own by reacting on information and following a set of rules that determine and select a feasible set of options and outcomes. And, in analogy to Christian (2018: 78), like the laws of human societies change from place to place and moment to moment, regional economic ecosystems appear as environments that have their own local rules that were not universal, and have to be read or decoded or studied. 


\subsection{The emergence of entrepreneurial ecosystems}

With the extant literature on entrepreneurial ecosystems, some important questions have not been asked yet or have not been sufficiently answered: How do ecosystems and in particular entrepreneurial ecosystems emerge and evolve over time? Are entrepreneurial ecosystems artificial and thus created from scratch or do they evolve by chance, or something in-between? Do entrepreneurial ecosystems follow an archetypical lifecycle model from birth and an initial phase towards phases with an increasing population up to a maximum followed by a starving decline and a potential re-emergence? Answers to these questions are essential for policy makers to implement adequate policy measures and instruments that support fluid ecosystems enabling the oscillation that occurs among entrepreneurs and intrapreneurs to ultimately generate regional growth and prosperity. Based on our lifecycle model, this paper aims to provide answers to these questions.

Our dynamic lifecycle model outlines why both entrepreneurial firms and established firms co-exist, how and why they are closely linked together forming ecosystems. In that, we argue that the lifecycle concept explains how ecosystems arise and how they work and provides a basic framework to analyze the formation, design, and evolvement of ecosystems. The initial "big bang" or starting point of our analysis is an idea and an individual's decision whether to exploit an idea externally and become an entrepreneur or internally within the established firms. Our lifecycle model combines the concepts of "intrapreneurship" and "entrepreneurship" within an occupational choice context (see Lucas, 1978): the decision to exploit an idea by becoming an entrepreneur or by still working in an established firm is shaped by the opportunity costs. Like one swallow does not make a summer and a single entrepreneur does not make an entrepreneurial ecosystem, we assume positive spillover effects of entrepreneurship, increasing the number of firms within regions. A trend towards exploiting new ideas by creating new firms will lead to an entrepreneurial ecosystem, while the opposite, the exploitation of ideas within established firms, will constitute a business ecosystem. Clearly, both entrepreneurial and business ecosystems are closely linked together by the individual decision process to exploit ideas externally or not.

Because individuals create firms and firms create ecosystems, our model helps to explain how entrepreneurial ecosystems arise and evolve over time, how and why they co-exist with business ecosystems, and whether or not entrepreneurial ecosystem survive or not. It is a stylized fact in economic research that entrepreneurial firms create and operate markets. Without entrepreneurial firms, market economies could not exist, since even established and incumbent firms started small as a new venture. And the new ventures created are the results of an individual's decision to create one, a process driven by exogenous factors like outside opportunities but also the result of an intellectual process. While there is an extensive debate on the influence of exogenous and endogenous factors shaping entrepreneurial opportunities and the decision to create a new firm or not, and whether exogenous factors are more or less important compared with the cognitive process of entrepreneurs, there is no doubt that the decision process starts with an initial "big bang"- the idea (see Brush et al., 2001).

It is also undisputed in economic theory that individuals choose to become entrepreneurs by working in established firms, which makes entrepreneurship endogenous (Baumol, 2010). As Spulber (2009: 1) states, firms are established endogenously by entrepreneurial actions, and since firms act as market makers by creating and operating markets, also markets are endogenous. Economic equilibria are thus the result of transacting internally in established firms and the creation of new firms and markets. Markets are thus endogenously shaped by the characteristics and actions of individuals and their relationships forming communities, social institutions, governments and networks, or an economic ecosystem. Firms operate in an ecosystem consisting of such communities, social institutions, networks and government, rules, and norms, which emerge and evolve over time. While some of the components and properties of an ecosystem are more or less exogenous but are endogenous on the long run, other components are endogenously shaped by actions and decisions made in the short run and are the result of interactions of individuals and the rather fixed properties. The nucleus of an ecosystem, the source of creation, and change of ecosystems is the decision process of how to generate and exploit ideas: whether ideas are generated and exploited internally in established firms or by establishing a new venture as a means to commercialize the idea. If the overwhelming amount of ideas in an ecosystem is generated and exploited internally, such an ecosystem could be labeled as a "business ecosystem." If the most 
relevant ideas are commercialized by creating new firms, start-up companies, we can talk of "entrepreneurial ecosystems." While neither business nor ecosystems exist in a pure form and are interlinked by the decision process of exploiting ideas internally or externally, both kinds of ecosystems exist and evolve following a codeterminate path. Business ecosystems and entrepreneurial ecosystems are thus characterized by complementarities and substitutional interrelations, leading to different patterns. It is the interrelatedness of the living actors, the economic agents, what separates economic ecosystems from economic markets - an important stylized fact which is almost neglected by the ecosystem literature so far.

\section{A dynamic lifecycle model of an entrepreneurial ecosystem}

In order to describe the evolution of an entrepreneurial ecosystem and thus capture its dynamic nature (see Brown \& Mason, 2017), we rely on the traditional concept of industry lifecycles as introduced by Vernon (1966). For simplicity, we assume that an entrepreneurial ecosystem evolves over time, passing several phases (see Fig. 1); starting with the introduction or the beginning of an entrepreneurial ecosystem (phase I), the growth phase (II), the maturity or stabilization phase (III), the decline phase (IV), and a subsequent reemergence phase $(\mathrm{V})$. We consider a reproduction rate as an elasticity of commercializing an idea inside an established firm (intrapreneurship) or outside by creating a new venture (entrepreneurship). The reproduction rate is thus an equivalent to an elasticity coefficient in a regional production function expressing the ratio of intrapreneurship and entrepreneurship. If the reproduction rate exceeds 1 , the entrepreneurial ecosystem is increasing or growing, if it equal to 1 , the entrepreneurial ecosystem is saturated, and declining when the reproduction rate falls below 1 . As long as the reproduction rate is larger than 1 , exploiting opportunities via new firm creation and entrepreneurship, the broader regional economic ecosystem as a nested ecosystem is dominated by the "entrepreneurial ecosystem" as a subset. When the reproduction rate falls below 1 , then the "business ecosystem" dominates the regional economic ecosystem. At the point of intersection, both ecosystems, the entrepreneurship ecosystem and the business ecosystem, contribute equally to the regional economic ecosystem.

This lifecycle model of a regional economic ecosystem helps to explain why, albeit neglected by many authors, even regions with a low rate of entrepreneurship may show high-performance measures, if the business ecosystem is at work and the exploitation of new ideas and knowledge is organized as an internal process (and vice versa).

\subsection{Phase I: The birth of an entrepreneurial ecosystem}

We follow Alfred Marshall and define an idea as the initial point, the "big bang" of an entrepreneurial ecosystem. Marshall (1920: 225) argues that "if one man starts a new idea, it is taken up by others and combined with suggestions of their own; and thus it becomes the source of further new ideas." An idea carried out by an individual, an idea as something virtual with distinctive new qualities, leading to new things with new properties. New things, even the best ideas, do not fall like manna from heaven. New things, new properties, and new qualities do not arrive out from nowhere or from nothing, but emerge from already existing things and forces that are arranged in new ways (Christian, 2018: 22). What holds for the largest known ecosystem, our universe, should even hold for every subset of ecosystems, even an entrepreneurial ecosystem. A new idea is consequently nothing else than a vision of a new arrangement of existing things and forces that yield the new properties, just as arranging letters or notes to new poems or songs, or both together. Like when we read a new poem or listen to a new piece of music, we think of a new form or structure with new qualities, of a new arrangement of what already exists: innovation is emergence. $^{3}$ In essence, it is a recombination of existing basic and applied knowledge that might ultimately stimulate the creation of new knowledge and ideas (see Leyden \& Menter, 2018).

In the initial phase, an economic agent, an individual agent, has an idea about how to arrange existing things in a new way and to convert this idea into some societal utility. Such "existing things" may be the effect of spillovers from other sources, like knowledge overlooked or neglected by others or something "which is in the air," citing Marshall (1920) again. This

\footnotetext{
$\overline{3}$ And very often, by chance or not, the new arrangements do not differ in large by hitherto existing arrangements.
} 

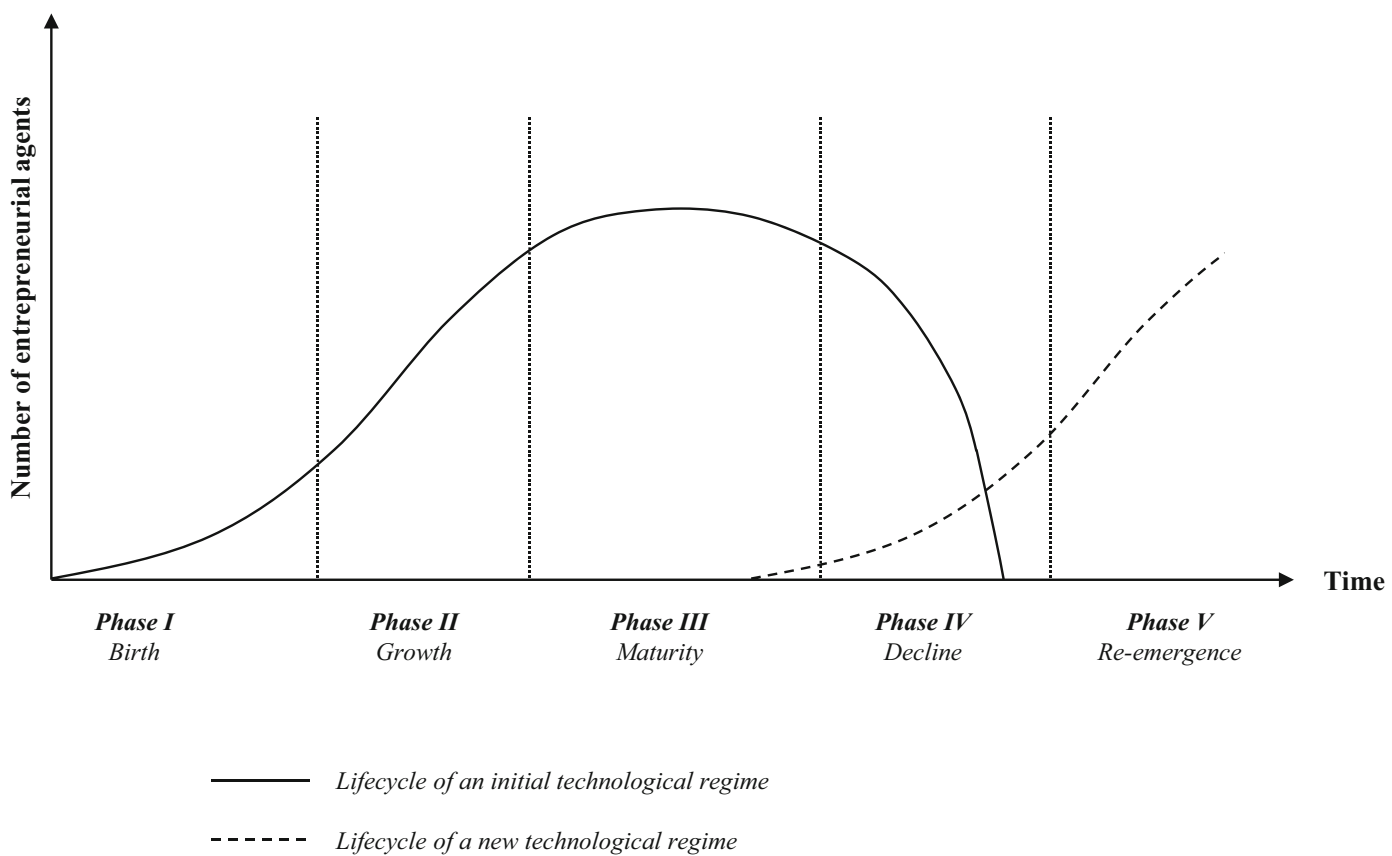

Fig. 1 A dynamic lifecycle model of an entrepreneurial ecosystem

individual has at least two options when converting an idea into societal and economic utility: either by exploiting the opportunity within an incumbent firm and acting as an intrapreneur or starting a new venture as an entrepreneur. We follow the rich and fruitful literature on entrepreneurial decision-making, based on opportunities (Kirzner, 1973; Schumpeter, 1934), the judgment of opportunities (Foss \& Klein, 2012), opportunity costs (Venkataraman, 1997), the discovery of entrepreneurial opportunities, and how and why the entrepreneurial decision process is shaped by individual differences (Shane, 2003). For simplicity, the opportunity costs consist mainly of the use of time and the income, influenced by individual factor levels like education, experience, or social position (status and ties). At the starting point, when the individual decides to exploit his or her idea by creating a new venture, the expected utility or value exceeds the opportunity costs. It is important to note that especially at the early stages of a new technological regime (see Breschi et al., 2000), opening up potential new markets in the long run, no incumbent firm might be available or willing to engage into this new technology, resulting in an individual decision to either start a new venture ("entrepreneurial ecosystem") or leave the idea unexploited.

To pursue uncertainty opportunities, individuals carefully evaluate the costs and benefits of becoming an entrepreneur or staying within an incumbent firm as an intrapreneur. To become an entrepreneur and exploit an idea by creating a new venture, individuals must believe that they will gain more than they are giving up (Venkataraman, 1997). As Shane puts it (2003: 62), "when people make a decision to exploit an entrepreneurial opportunity, they do so because they believe that the expected value of exploitation (both monetary and psychic) exceeds the opportunity costs of alternative uses of their time plus the premiums that they would like for bearing uncertainty and illiquidity." Consequently, the more likely individuals are to exploit an opportunity as an entrepreneur, the greater is the value that they expect to receive from exploiting the idea outside an incumbent firm by creating a new venture. This expected value is shaped by the regional or local economic ecosystem, in particular by the nature of the opportunity, the industry and market conditions, and the environment with its institutions, norms, and rules. All three factors are archetypical for ecosystems, namely the individual agent, the interrelations and interactions with other economic agents and the nonliving environment.

A pivotal point in an economy in general and in particular in a regional economic ecosystem is knowledge spillovers and the sources of knowledge spillovers (Acs et al., 2013; Ghio et al., 2015; Audretsch \& Lehmann, 2005). Literature has identified two main 
sources of knowledge production: academic research institutions and established firms (see Audretsch \& Feldman, 1996). The knowledge they produce could only in small parts be exploited within their boundaries, or outside by new venture creation. In this stadium, new venture creation and entrepreneurship may occur in two ways. First, by employees (even academics are employees of their universities) by exploiting opportunities originating in knowledge overlooked or neglected by their organization. Second, by spin-offs, when the proprietary company or university favors individuals or teams to exploit their ideas and opportunities outside the firm by creating a new company. As Fabel (2004) shows, entrepreneurial spin-offs constitute a persistent response to the established corporations' failure in organizing teamwork in high-risk and human capitalintensive industries.

Given such a high risk and uncertain production environment, like in the ICT and high-tech industries, the verification of the team members' abilities will plausibly be enhanced if the evaluation is carried out by the team members themselves, and not by their boss. Even if verification is in principle possible, Fabel (2004) argues that it is necessary to provide incentives to specialize on this task. While wage incentives for specialized human resource managers in large corporations cannot draw on direct measures of their recruitment success (Weinberg, 2001; Zingheim \& Schuster, 2000), in entrepreneurial firms, the motivation to select appropriately is directly linked to the manager-owners' residual income claims (Lehmann, 2006). Consequently, equity-like remuneration, like shares or option plans, is then better aligned with tasks than wage incentives (see Lehmann, 2006). Moreover, organizing the team not only requires selective recruiting. It will also be necessary to dismiss individuals who, upon being initially hired, turn out not to fit perfectly into the team. In a bureaucratic hierarchy, detecting and dismissing people who do not (perfectly) match with the team is associated with high transaction costs, leading to adverse effects. In young and entrepreneurial firms, employees' work contracts are similar to self-employment and hiring and firing is the rule and not the exception. Prat (2002) shows that hierarchies with ability-matched teams are dominant in production environments and characterized by positive complementarities between specialized tasks. The perspective to become owners themselves limits the exploitation risk and, therefore, enhances the incentives to specialize for young managers. Then,
Bhidé (2000: 139-140, 367-368) again reports the particular importance of such teamwork in corporate ventures. Thus, entrepreneurial firms could more easily react to exogenous shocks and environmental changes than incumbent firms.

To conclude, intrapreneurial activities, the exploitation of new ideas and opportunities, are hard to monitor, induce adverse team effects, often conflicts with the corporate culture and finally, intrapreneurs could not be payed as bureaucrats, which favors the concept of entrepreneurship (Weinberg, 2001; Zingheim, \& Schuster 2000). Fabel (2004) shows that the inflexibility of a firm's wage structure to sufficiently differentiate, reward, and encourage entrepreneurial activities fosters the spin-off of teams: while the wages are now paid outside the firm, the possible rewards when the spin-off is successfully operating could be at least partly absorbed by the stakes hold with the spin-off.

Spin-offs and new venture creation are then the core base that forms an entrepreneurial ecosystem. The first phase is thus characterized by a growing number of entrepreneurial firms and spin-offs in the region. As Shane (2003), among others, points out, entrepreneurship does not occur in isolation. A necessary (but not sufficient) attribute of an entrepreneurial ecosystem is the manifold relationships among the entrepreneurs. Entrepreneurs and entrepreneurial firms constitute a complementary set of variables in that increasing one variable increases the outcome of another (see Roberts, 2004). This lowers the opportunity costs of new venture creation, either by individuals or spin-off teams. Within a rather short period of time, the number of entrepreneurial activities increases within a region, constituting what academics label an "entrepreneurial ecosystem."

\section{- Proposition 1: The starting point of an entrepre- neurial ecosystem - the birth stage—is an idea that may not be exploited within an incumbent firm, resulting in new venture creation.}

\subsection{Phase II: The growth of an entrepreneurial ecosystem}

The second stage of our dynamic lifecycle model is the growth phase where each element in the entrepreneurial ecosystem starts to become more specialized and targeted towards entrepreneurship. A vibrant entrepreneurial scene, resembling an archetypical 
"entrepreneurial ecosystem" where all the different economic agents, like venture capitalists, consultants and lawyers, entrepreneurship policies (Lehmann \& Menter, 2018a,b; Audretsch et al., 2016, 2019a; Cunningham et al., 2019a), incubators, and accelerators are at work and educational institutions start to offer entrepreneurship-specific programs to foster new firm creation and location (Audretsch \& Lehmann, 2005; Audretsch et al. 2019b). Financial capital becomes more readily available, and access to financial capital becomes increasingly less restrictive. Human capital becomes more entrepreneurially minded and successful entrepreneurs begin to function as role models for potential nascent entrepreneurs, leading to a herd behavior effect: being or becoming an entrepreneur generates an individual value per se, a nonmonetary benefit of being an entrepreneur. The regional culture strengthens entrepreneurship itself and is now part of the regional subculture scene and entrepreneurial networks expand and become denser (Lehmann \& Seitz, 2017) and as a result, societal norms may change in favor of a regional "entrepreneurship society" (Audretsch, 2007).

The important source to grow is human capital and an adequate labor force. Specific human capital, technological know-how, and employment systems now play key roles in these new enterprises (Rajan \& Zingales, 2000) as they can allow for competitive advantages if successfully implemented. Entrepreneurial firms provide both strong incentives to specifically invest in the innovation process and corresponding selection devices to identify opportunities more successfully as compared with incumbents (Fabel, 2004; Rajan \& Zingales, 2001a,b). Prat (2002) demonstrates the pivotal role of adequate recruiting for entrepreneurial firms and case studies show that - during the growth phase following the immediate birth period - recruiting experienced managers from established firms constituted a key success factor (Bhidé, 2000) and "unusual judgement or perceptiveness" in employee selection became a strategic advantage of successfully operating entrepreneurial firms (Bhidé 2000: 108). During this phase, the entrepreneurial ecosystem evolves to include also national and international opportunities, as reflected by the visibility of the first serial entrepreneurs and unicorns, i.e., entrepreneurial firms with a market value beyond a billion US\$. While new firms constantly enter the "entrepreneurial ecosystem" and the former start-up companies grow, others are leaving the market.
At the same time, established firms have to renew and redefine their routines and norms towards a "corporate entrepreneurship" culture (Kuratko et al., 1990, 2014, 2015; Covin \& Miles, 1999). Takeovers of startup and entrepreneurial firms now allow for acquiring innovations, such as new and sophisticated variations of products or services already offered by incumbents (Fabel, 2004; Henkel et al., 2015; Lehmann and Schwerdtfeger, 2016), that already have proven their viability and subsequently can be brought to the market by exploiting incumbents' advantages such as broader resource bases, sufficient funding, and economies of scale and scope in production, and other value chain activities. The tendency to re-integrate entrepreneurial firms characterizes the end of the second phase.

\section{- Proposition 2: Following the immediate birth period, the growth stage is characterized by the emergence of an entrepreneurship culture, en- couraging further individuals to start their own business.}

\subsection{Phase III: The maturity and stabilization of an entrepreneurial ecosystem}

In the third stage, the entrepreneurial ecosystem reaches a phase of maturity and stabilization which is characterized by a smaller number of new entrepreneurial firms entering the market and a larger number of firm exits. At the end of stage two, access to financial resources does not serve as a prohibitive entry barrier and restriction, leading to adverse effects of market entries. The "window of opportunity," as described by Ritter (1991), has been opened widely and attracted individuals and the creation of new firms with questionable quality (Baumol, 1996; Litwin \& Phan, 2013), leading to pooling-equilibrium of qualities (Antony et al., 2017). In this phase, market opportunities and networks start to weaken, increasing the opportunity costs of becoming an entrepreneur or working within an entrepreneurial firm. Thus, some ventures mature, becoming more formally structured and bureaucratic, less flexible, and dynamic. The decline in the number of new firm creation and entries increases the opportunity cost of selfemployment and lowers the opportunity costs for other types of employment, like returning back to incumbent and established firms. Investor confidence begins to wane, financial capital becomes harder to access, and 
IPO activities start declining (Meoli et al., 2013; Bonardo et al., 2010).

At the same time, established companies increase their effort to re-integrate entrepreneurial firms, leading to a win-win situation for both, entrepreneurial firms and incumbent firms (Lehmann \& Schwerdtfeger, 2016). While young and entrepreneurial firms' innovation endeavors are assumed to be more likely to create breakthroughs, these firms often fail to bring their innovations to the market. Large and established firms have the financial resources to invest in new technologies, but they often lack new and radical innovations. Since startup and entrepreneurial innovation is more radical than that of established firms, Granstrand and Sjölander (1990) suggest a division of scientific labor between entrepreneurial and established firms. Such a division of labor implicitly defines their roles as targets for acquisitions so that takeovers may lead to a win-win situation for both parties (Gans \& Stern, 2000; Blonigen and Taylor, 2000). Being taken over not only reflects and values the past performance of the top management team positively (Gans \& Stern, 2000; Colombo et al., 2010) but also promotes and supports established firms to attract critical technological resources by taking over young high-tech firms, leading to a win-win situation or match for both firms - when the new venture could be successfully re-integrated. However, re-integrating of entrepreneurial firms is not a success story per se. As noted by Bhidé (2000: 324) the "corporate culture" of established firms may still prevent the installment of ability-matched teams of superior quality. Thus, the degree to which re-integration will occur is also determined by the firms' integrating abilities to differentiate wages.

This stage reflects the intersection with the regional business ecosystem, the transition and change from the entrepreneurial to the business ecosystem. The performance of the business ecosystems as a subset of the regional economic ecosystem becomes more significant compared with the entrepreneurial ecosystem. The economic agents as appeared in the first two stages are still at work, but on a less dynamic and vibrant way - and become established players within the regional economic ecosystem. Like vegan food once was a characteristic peculiarity of an entrepreneurship subculture, it has now become a main street trend (Lehmann \& Seitz, 2017).

\section{- Proposition 3: The maturity and stabilization phase reflects the intersection between an}

entrepreneurial ecosystem and a business ecosystem, as new venture creation becomes less attractive and incumbent firms increase their efforts to re-integrate entrepreneurial firms.

\subsection{Phase IV: The decline of an entrepreneurial ecosystem}

The fourth stage is characterized by a reverse way in exploiting ideas and opportunities. New ideas and knowledge are now mainly exploited within established firms, and new venture creation to exploit opportunities resembles an exception and not the rule. New firms enter the market, but resemble more traditional companies than entrepreneurial firms. Even when this phase is characterized by a low rate of market entry, the declining phase of an entrepreneurial ecosystem is not equivalent to a decline of the regional economic system, or regional competitiveness and wealth. It is just that the main drivers of the regional economic ecosystem are now established firms, either because once entrepreneurial firms mature and have grown or the incumbent firms re-gain their strategic advantage or both. Like a mitochondria containing all the genetic information, entrepreneurial firms are now totally re-integrated in a larger body, i.e., the incumbent firm, offering the genetic code to the acquirer.

This phase is characterized by the establishment of technological standards, substantiating the existing technological regime that can be defined as "a particular combination of some fundamental properties of technologies: opportunity and appropriability conditions; degrees of cumulativeness of technological knowledge; and characteristics of the relevant knowledge base" (Malerba \& Orsenigo, 1997: 94). Radical innovations are rare in this phase and incumbent firms rather focus on incremental innovations. This in turn opens up new (unexploited) opportunities for potential entrepreneurs, inducing the basis for a re-emergence phase of an entrepreneurial ecosystem resulting in the genesis of a new technological regime.

- Proposition 4: The decline phase characterizes the final transition from an entrepreneurial ecosystem towards a business ecosystem, as new ideas are now mainly exploited within incumbent firms. 
4.5 Phase V: The re-emergence of an entrepreneurial ecosystem

The entrepreneurial lifecycle may end in the fourth stage, becoming a business ecosystem with wellestablished companies, routines, and norms. Hitherto, dynamic and entrepreneurial regional ecosystems now tend to emerge to industrial clusters and clustering districts. Prominent examples are the regional dispersion of medium-sized companies in Germany, France, or Italy, grouping around research institutions with a focus on applied sciences (see Audretsch \& Lehmann, 2016). While those regions often exhibit strong competitive firms (often so-called hidden champions and world market leaders in their niches), they exploit their knowledge generated and absorbed internally - as intrapreneurs (Audretsch et al., 2018). What lacks is the exploitation of ideas and knowledge outside firm boundaries, coordinated and motivated by the local market forces; there is a lack of entrepreneurship.

Another path is what is called the "re-emergence" in a lifecycle (see Cope, 2011); the "re-emergence" of exploiting ideas and knowledge externally via entrepreneurship. Assuming the same mechanisms at work as in the first stage, it may be worthwhile for some individuals to exploit ideas outside firm boundaries, either as a spin-off or new venture creation. In this case, the entrepreneurial ecosystem lifecycle starts again, but in a different way. While in the first stage, the supporting institutions, networks, routines, and norms had to be established over time, they are now "in the air," still there, awaiting a re-emergence (see Fritsch et al., 2019). Entrepreneurial culture has been established in the region and within the incumbent firms, and learning experience could be easily retrieved. Established firms are now ready to foster entrepreneurship, starting in the earliest stages. With firm-owned accelerators, they support employees and external entrepreneurs in identifying new ideas and how to exploit them. Incubators provide support to grow up and survive the first stage more easily. All the economic agents supporting entrepreneurial ecosystem, like many wheels interlocked together, will seamlessly engage with the maximum benefit for all those involved in the entrepreneurial ecosystem (see $\mathrm{Li}$ et al., 2016; Isaksen, 2016). This may lead to a continuous circle, with the "Silicon Valley" as a role model where new firms enter the market following a sinus curve, former entrepreneurial firms maturate over the years, like Amazon, Alphabet, Microsoft or Apple, now becoming incumbent firms as sources of knowledge for entrepreneurs, producers of spin-offs, providers of accelerators and incubators, and finally as acquirers of successful and promising start-ups. Within this iterative process, initial technological regimes might be relieved by new technological regimes, opening up new opportunities that may either be exploited by entrepreneurs or intrapreneurs (see O'Connor et al., 2018).

- Proposition 5: Based on the already existing entrepreneurship infrastructure, the re-emergence phase opens up new opportunities for entrepreneurs to exploit uncommercialized ideas from incumbent firms, replacing the initial technological regime.

\section{Conclusions and future research avenues}

The purpose and contribution of this paper is to present a dynamic entrepreneurial ecosystem lifecycle model. This model addresses one of the core criticisms of entrepreneurial ecosystems to date of not taking into account or appreciating the "complexity of the dynamics" as argued by Brown and Mason (2017: 26). Our lifecycle model makes the following contributions.

First, we build on Mack and Mayer's (2016) evolutionary model of entrepreneurial ecosystems by capturing the oscillation that occurs among entrepreneurs and intrapreneurs through the different phases of our lifecycle model. This oscillation enables the secondphase evolution - growth - and contributes to the vibrancy of the entrepreneurial ecosystem within a regional context. Moreover, our lifecycle model addresses how entrepreneurial ecosystems emerge and evolve over time and we introduce a fifth phase of re-emergence. In particular, we argue that the emergence of ecosystems is based on individuals making a decision to become an entrepreneur. The individual manifestation of this decision is made through the routes of new venture creation or through intrapreneurship within an existing firm. Therefore, we argue that entrepreneurial ecosystems can emerge by chance or they can be created through individual decision-making to purse a "window of opportunity" as described by Ritter (1991).

Second, our model highlights that entrepreneurial opportunities evolve and are available to be exploited by entrepreneurs and intrapreneurs over several phases 
of our lifecycle model. How entrepreneurs and intrapreneurs respond to these opportunities contributes to the dynamic nature of entrepreneurial ecosystems. Through these lifecycle phases, entrepreneurs and intrapreneurs use various approaches to exploit such opportunities and they evolve to maximize the market opportunities as well as leveraging the resources within their regional context to support their individual or organizational entrepreneurial efforts. In particular, our model posits that it is new venture creation and spin-off firms during the birth phase that provide the core and critical base and foundation for the establishment of an entrepreneurial ecosystem within a region. The combination of the individual entrepreneurial decision-making and resultant actions over the lifecycle phases contributes to the dynamism within entrepreneurial ecosystems. This, we suggest, forms the core of an entrepreneurial ecosystems and is a key factor that contributes to the activities and sustainability of ecosystems. In essence, our model also contributes to addressing another core criticism of entrepreneurial ecosystems of how individual contribute to activities (see Spigel, 2017: 143).

Third, our lifecycle model suggests that entrepreneurial ecosystems do follow an archetypical lifecycle model from birth and an initial phase towards phases with an increasing population up to a maximum followed by a subsequent decline as the market and entrepreneurial opportunities also decline, followed by a potential reemergence. A more effective conceptualization and measurement of the lifecycle of entrepreneurial ecosystems is established through entrepreneurial opportunities or innovation capital (see Audretsch \& Link, 2018). This builds on Autio et al.'s (2018) suggestion for the need for other measurement approaches. Moreover, entrepreneurial opportunities exist throughout the entrepreneurial ecosystem lifecycle and individuals and firms draw on different sets of resources and supports to exploit these opportunities. We suggest that during the second and third phase, some entrepreneurs and intrapreneurs may also be exploring opportunities that could establish new entrepreneurial ecosystems around a particular technological domain (re-emergence) or exploit a narrower and or niche market opportunities. Such actions and behaviors may lead to the tentative formation of future entrepreneurial ecosystems. These activities also contribute to the dynamic nature of entrepreneurial ecosystems and to the sustainability of the region where these entrepreneurs and intrapreneurs are located. Our lifecycle model thus enables a deep contextualization of entrepreneurial ecosystems as argued by Spigel and Harrison (2018) which has been lacking to date within the extant literature.

Fourth, one of the ongoing criticisms of entrepreneurial ecosystems is that studies to date have focused on single settings (Alvedalen \& Boschma, 2017). Our lifecycle model can be applied to a single setting such as a region or at a more macro level where there are numerous entrepreneurial systems. Hence, the investigation of a multi-stakeholder, multi-governance environment would be feasible, analyzing the interdependencies among various actors and institutions.

We suggest future research with regard to the adoption of our lifecycle model to overcome some of the criticisms posited to date about entrepreneurial ecosystems and to particularly capture their dynamic nature. Our lifecycle model can be used to undertake international comparisons of ecosystems at different phases of development in the same or different sectors. Future studies using the lifecycle can focus on how entrepreneurs and intrapreneurs access or are influenced by institutional and regional supports through the different lifecycle phases in making their decisions to purse and exploit opportunities. For example, are specific institutional and regional supports more effective than others in accelerating entrepreneurs to exploit opportunities? What learning is shared collectively among ecosystem actors through the different lifecycle phases and how does this influence the building of trust and networks within and among various regional entrepreneurial ecosystems?

Another strand of research is to explore the narratives and identifiers (see Roundy, 2016) that are used by entrepreneurs and policy makers in describing an entrepreneurial ecosystem through the lifecycle and what language is used to describe their success and vibrancy. For example, which actors within the entrepreneurial ecosystem create the narrative to describe the emergence and evolution of an entrepreneurial ecosystem? What is the purpose of this narrative and who benefits within the entrepreneurial ecosystem? During the decline phase of our lifecycle model, how do ecosystems use narrative and language in their approaches to maintain some vibrancy within an entrepreneurial ecosystem?

Further research is needed to better understand at the macro, meso, and micro levels how entrepreneurial ecosystems actually make the transition through the different phases of the lifecycle and in particular what actions entrepreneurial ecosystem agents need to undertake to stave off decline or trigger the re-emergence 
phase. Using the lifecycle model with comparative data would enable the identification of trigger points or events that enable the entrepreneurial ecosystem to evolve from one phase to another. For example, is there a threshold level of new venture creation and spin-off firms required for entrepreneurial ecosystem to evolve from birth to growth?

Finally, strands of future research using the lifecycle approach could focus on themes of entrepreneurial behavior among entrepreneurial ecosystems actors and how this evolves over time. The impact of business failure on the evolution of entrepreneurial ecosystem and in particular how regenerative entrepreneurship influences and shapes growth, maturity, and decline phases of the entrepreneurial ecosystem lifecycle are further fruitful avenues of research. Focusing on the contextualized experiences of individual actors through the different phases of the entrepreneurial ecosystem lifecycle can yield further valuable insights. For example, are there gender differences experienced by entrepreneurs and intrapreneurs within and across different regions? How do scientists leverage entrepreneurial ecosystems to pursue excellence in science and research as well as knowledge and technology transfer through the different lifecycle phases? A plurality of data collection methods and a broad set of estimation techniques might thereby help to derive further insights into this highly relevant field of research (see Cunningham et al., 2017).

Funding Information Open Access funding provided by Projekt DEAL.

Open Access This article is licensed under a Creative Commons Attribution 4.0 International License, which permits use, sharing, adaptation, distribution and reproduction in any medium or format, as long as you give appropriate credit to the original author(s) and the source, provide a link to the Creative Commons licence, and indicate if changes were made. The images or other third party material in this article are included in the article's Creative Commons licence, unless indicated otherwise in a credit line to the material. If material is not included in the article's Creative Commons licence and your intended use is not permitted by statutory regulation or exceeds the permitted use, you will need to obtain permission directly from the copyright holder. To view a copy of this licence, visit http://creativecommons.org/licenses/by/4.0/.

\section{References}

Acs, Z. J., Audretsch, D. B., \& Lehmann, E. E. (2013). The knowledge spillover theory of entrepreneurship. Small Business Economics, 41(4), 757-774.
Acs, Z. J., Autio, E., \& Szerb, L. (2014). National systems of entrepreneurship: measurement issues and policy implications. Research Policy, 43(3), 476-494.

Acs, Z. J., Estrin, S., Mickiewicz, T., \& Szerb, L. (2018). Entrepreneurship, institutional economics, and economic growth: an ecosystem perspective. Small Business Economics, 51(2), 501-514.

Acs, Z. J., Stam, E., Audretsch, D. B., \& O’Connor, A. (2017a). The lineages of the entrepreneurial ecosystem approach. Small Business Economics, 49(1), 1-10.

Acs, Z. J., Szerb, L., \& Autio, E. (2017b). Enhancing entrepreneurial ecosystems: a GEI approach to entrepreneurship policy. In Z. J. Acs, L. Szerb, \& E. Autio (Eds.), Global Entrepreneurship and Development Index 2016, (pp. 6576), springer briefs in economics. Heidelberg: Springer.

Alvedalen, J., \& Boschma, R. (2017). A critical review of entrepreneurial ecosystems research: towards a future research agenda. European Planning Studies, 25(6), 887-903.

Antony, J., Klarl, T., \& Lehmann, E. E. (2017). Productive and harmful entrepreneurship in a knowledge economy. Small Business Economics, 49(1), 189-202.

Audretsch, D. B. (1998). Agglomeration and the location of innovative activity. Oxford Review of Economic Policy, 14(2), 18-29.

Audretsch, D. B. (2007). The entrepreneurial society. New York: Oxford University Press.

Audretsch, D. B., \& Belitski, M. (2017). Entrepreneurial ecosystems in cities: establishing the framework conditions. The Journal of Technology Transfer, 42(5), 1030-1051.

Audretsch, D. B., \& Feldman, M. P. (1996). R\&D spillovers and the geography of innovation and production. The American Economic Review, 86(3), 630-640.

Audretsch, D. B., Keilbach, M., \& Lehmann, E. E. (2006). Entrepreneurship and economic growth. New York: Oxford University Press.

Audretsch, D. B., \& Lehmann, E. E. (2005). Does the knowledge spillover theory of entrepreneurship hold for regions? Research Policy, 34(8), 1191-1202.

Audretsch, D. B., \& Lehmann, E. E. (2016). The seven secrets of Germany: economic resilience in an era of global turbulence. New York: Oxford University Press.

Audretsch, D. B., Lehmann, E. E., \& Menter, M. (2016). Public cluster policy and new venture creation. Economia e Politica Industriale, 43(4), 357-381.

Audretsch, D. B., Lehmann, E. E., Menter, M., \& Seitz, N. (2019a). Public cluster policy and firm performance: evaluating spillover effects across industries. Entrepreneurship and Regional Development, 31(1-2), 150-165.

Audretsch, D. B., Cunningham, J. A., Kuratko, D. F., Lehmann, E. E., \& Menter, M. (2019b). Entrepreneurial ecosystems: economic, technological, and societal impacts. The Journal of Technology Transfer, 44(2), 313-325.

Audretsch, D. B., Lehmann, E. E., \& Schenkenhofer, J. (2018). Internationalization strategies of hidden champions: lessons from Germany. Multinational Business Review, 26(1), 2-24.

Audretsch, D. B., \& Link, A. N. (2018). Innovation capital. The Journal of Technology Transfer, 43(6), 1760-1767.

Audretsch, D. B., \& Link, A. N. (2019). Sources of knowledge and entrepreneurial behavior. Toronto: University of Toronto Press. 
Auerswald, P. E. (2015). Enabling entrepreneurial ecosystems: insights from ecology to inform effective entrepreneurship policy. Kauffman Foundation Research Series on city, metro, and regional entrepreneurship.

Auerswald, P. E., \& Dani, L. (2017). The adaptive life cycle of entrepreneurial ecosystems: the biotechnology cluster. Small Business Economics, 49(1), 97-117.

Autio, E., \& Levie, J. (2017). Management of entrepreneurial ecosystems. The Wiley Handbook of Entrepreneurship.

Autio, E., Nambisan, S., Thomas, D. W. L., \& Wright, M. (2018). Digital affordances, spatial affordances, and the genesis of entrepreneurial ecosystems. Strategic Entrepreneurship Journal, 12(1), 72-95.

Baumol, W. J. (1996). Entrepreneurship: productive, unproductive, and destructive. Journal of Business Venturing, 11(1), 3-22.

Baumol, W. J. (2010). The microtheory of innovative entrepreneurship. Princeton: Princeton University Press.

Bhidé, A. V. (2000). The origin and evolution of new businesses. New York: Oxford University Press.

Blonigen, B. A., \& Taylor, C. T. (2000). R\&D intensity and acquisitions in high-technology industries: evidence from the US electronic and electrical equipment industries. The Journal of Industrial Economics, 48(1), 47-70.

Bonardo, D., Paleari, S., \& Vismara, S. (2010). The M\&A dynamics of European science-based entrepreneurial firms. The Journal of Technology Transfer, 35(1), 141-180.

Borissenko, Y., \& Boschma, R. (2016). A critical review of entrepreneurial ecosystems: towards a future research agenda. Papers in Evolutionary Geography, 1-21.

Braunerhjelm, P., Ding, D., \& Thulin, P. (2018). The knowledge spillover theory of intrapreneurship. Small Business Economics, 51(1), 1-30.

Breschi, S., Malerba, F., \& Orsenigo, L. (2000). Technological regimes and Schumpeterian patterns of innovation. The Eonomic Journal, 110(463), 388-410.

Brown, R., \& Mason, C. (2017). Looking inside the spiky bits: a critical review and conceptualisation of entrepreneurial ecosystems. Small Business Economics, 49(1), 11-30.

Bruns, K., Bosma, N., Sanders, M., \& Schramm, M. (2017). Searching for the existence of entrepreneurial ecosystems: a regional cross-section growth regression approach. Small Business Economics, 49(1), 31-54.

Brush, C. G., Greene, P. G., \& Hart, M. M. (2001). From initial idea to unique advantage: the entrepreneurial challenge of constructing a resource base. Academy of Management Perspectives, 15(1), 64-78.

Christian, D. (2018). Origin story: a big history of everything. Hachette UK.

Ciccone, A. (2002). Agglomeration effects in Europe. European Economic Review, 46(2), 213-227.

Colombelli, A., Paolucci, E., \& Ughetto, E. (2019). Hierarchical and relational governance and the life cycle of entrepreneurial ecosystems. Small Business Economics, 52(2), 505-521.

Colombo, M. G., Dagnino, G. B., Lehmann, E. E., \& Salmador, M. (2019). The governance of entrepreneurial ecosystems. Small Business Economics, 52(2), 419-428.

Colombo, M., Mustar, P., \& Wright, M. (2010). Dynamics of science-based entrepreneurship. The Journal of Technology Transfer, 35(1), 1-15.
Cope, J. (2011). Entrepreneurial learning from failure: An interpretative phenomenological analysis. Journal of Business Venturing, 26(6), 604-623.

Covin, J. G., \& Miles, M. P. (1999). Corporate entrepreneurship and the pursuit of competitive advantage. Entrepreneurship Theory and Practice, 23(3), 47-63.

Cumming, D., Werth, J. C., \& Zhang, Y. (2019). Governance in entrepreneurial ecosystems: venture capitalists vs. technology parks. Small Business Economics, 52(2), 455-484.

Cunningham, J. A., Menter, M., \& Young, C. (2017). A review of qualitative case methods trends and themes used in technology transfer research. The Journal of Technology Transfer, 42(4), 923-956.

Cunningham, J. A., Menter, M., \& O'Kane, C. (2018). Value creation in the quadruple helix: a micro level conceptual model of principal investigators as value creators. $R \& D$ Management, 48(1), 136-147.

Cunningham, J. A., Lehmann, E. E., Menter, M., \& Seitz, N. (2019a). The impact of university focused technology transfer policies on regional innovation and entrepreneurship. The Journal of Technology Transfer, 44(5), 1451-1475.

Cunningham, J. A., Menter, M., \& Wirsching, K. (2019b). Entrepreneurial ecosystem governance: a principal investigator-centered governance framework. Small Business Economics, 52(2), 545-562.

Ellison, G., \& Glaeser, E. L. (1999). The geographic concentration of industry: does natural advantage explain agglomeration? American Economic Review, 89(2), 311-316.

Fabel, O. (2004). Spinoffs of entrepreneurial firms: an o-ring approach. Journal of Institutional and Theoretical Economics, 160(3), 416-438.

Foss, N. S., \& Klein, P. G. (2012). Organizing entrepreneurial judgement. Cambridge: Cambridge University Press.

Fritsch, M., Sorgner, A., Wyrwich, M., \& Zazdravnykh, E. (2019). Historical shocks and persistence of economic activity: evidence on self-employment from a unique natural experiment. Regional Studies, 53(6), 790-802.

Gans, J. S., \& Stern, S. (2000). Incumbency and R\&D incentives: licensing the gale of creative destruction. Journal of Economics and Management Strategy, 9(4), 485-511.

Ghio, N., Guerrini, M., Lehmann, E. E., \& Rossi-Lamastra, C. (2015). The emergence of the knowledge spillover theory of entrepreneurship. Small Business Economics, 44(1), 1-18.

Granstrand, O., \& Sjölander, S. (1990). The acquisition of technology and small firms by large firms. Journal of Economic Behavior \& Organization, 13(3), 367-386.

Henkel, J., Rønde, T., \& Wagner, M. (2015). And the winner isacquired. Entrepreneurship as a contest yielding radical innovations. Research Policy, 44(2), 295-310.

Ireland, R. D., Covin, J. G., \& Kuratko, D. F. (2009). Conceptualizing corporate entrepreneurship strategy. Entrepreneurship Theory and Practice, 33(1), 19-46.

Isaksen, A. (2016). Cluster emergence: combining pre-existing conditions and triggering factors. Entrepreneurship and Regional Development, 28(9-10), 704-723.

Isenberg, D. (2011). The entrepreneurship ecosystem strategy as a new paradigm for economy policy: principles for cultivating entrepreneurship, Babson entrepreneurship ecosystem project, Babson college, Babson Park: MA.

Kirzner, I. M. (1973). Competition and entrepreneurship. Chicago: University of Chicago Press. 
Klepper, S. (1997). Industry life cycles. Industrial and Corporate Change, 6(1), 145-182.

Kshetri, N. (2014). Developing successful entrepreneurial ecosystems: lessons from a comparison of an Asian tiger and a Baltic tiger. Baltic Journal of Management, 9(3), 330-356.

Kuckertz, A. (2019). Let's take the entrepreneurial ecosystem metaphor seriously! Journal of Business Venturing Insights, 11, 1-7. https://doi.org/10.1016/j.jbvi.2019.e00124.

Kuratko, D. F., Hornsby, J. S., \& Covin, J. G. (2014). Diagnosing a firm's internal environment for corporate entrepreneurship. Business Horizons, 57(1), 37-47.

Kuratko, D., Hornsby, J. F., \& Hayton, J. (2015). Corporate entrepreneurship: the innovative challenge for a new global economic reality. Small Business Economics, 45(2), 245253.

Kuratko, D. F., Montagno, R. V., \& Hornsby, J. S. (1990). Developing an intrapreneurial assessment instrument for an effective corporate entrepreneurial environment. Strategic Management Journal, 11, 49-58.

Lehmann, E. E. (2006). Corporate governance in new enterprises or: why do some CEOs hold large equity stakes while others are paid through stock options? Journal of Business Economics, 5, 21-36.

Lehmann, E. E., \& Menter, M. (2018a). Public cluster policy and neighboring regions: beggar-thy-neighbor? Economics of Innovation and New Technology, 27(5-6), 420-437.

Lehmann, E. E., \& Menter, M. (2018b). Public cluster policy and performance. The Journal of Technology Transfer, 43(3), $558-592$

Lehmann, E. E., \& Schwerdtfeger, M. T. (2016). Evaluation of IPO-firm takeovers: an event study. Small Business Economics, 47(4), 921-938.

Lehmann, E. E., \& Seitz, N. (2017). Freedom and innovation: a country and state level analysis. The Journal of Technology Transfer, 42(5), 1009-1029.

Leyden, D. P., \& Menter, M. (2018). The legacy and promise of Vannevar Bush: rethinking the model of innovation and the role of public policy. Economics of Innovation and New Technology, 27(3), 225-242.

Li, M., Goetz, S. J., Partridge, M., \& Fleming, D. A. (2016). Location determinants of high-growth firms. Entrepreneurship and Regional Development, 28(1-2), 97-125.

Liguori, E., Bendickson, J., Solomon, S., \& McDowell, W. C. (2019). Development of a multi-dimensional measure for assessing entrepreneurial ecosystems. Entrepreneurship and Regional Development, 31(1-2), 7-21.

Litwin, A. S., \& Phan, P. H. (2013). Quality over quantity: reexamining the link between entrepreneurship and job creation. ILR Review, 66(4), 833-873.

Lucas, R. E. (1978). On the size distribution of business firms. The Bell Journal of Economics, 9(2), 508-523.

Mack, E., \& Mayer, H. (2016). The evolutionary dynamics of entrepreneurial ecosystems. Urban Studies, 53(10), 21182133.

Malerba, F., \& Orsenigo, L. (1997). Technological regimes and sectoral patterns of innovative activities. Industrial and Corporate Change, 6(1), 83-118.

Mason, C., \& Brown, R. (2014). Entrepreneurial ecosystems and growth oriented entrepreneurship. Paris: Final Report to OECD.
Marshall, A. (1920). Principles of economics. London: Macmillan.

Meoli, M., Paleari, S., \& Vismara, S. (2013). Completing the technology transfer process: M\&As of science-based IPOs. Small Business Economics, 40(2), 227-248.

O'Connor, A., Stam, E., Sussan, F., \& Audretsch, D. B. (2018). Entrepreneurial ecosystems: the foundations of place-based renewal. In A. O'Connor, E. Stam, F. Sussan, \& D. B. Audretsch (Eds.), Entrepreneurial ecosystems. international studies in entrepreneurship (pp. 1-21). Cham: Springer.

Oh, D. S., Phillips, F., Park, S., \& Lee, E. (2016). Innovation ecosystems: a critical examination. Technovation, 54, 1-6.

Prat, A. (2002). Should a team be homogeneous? European Economic Review, 46, 1187-1207.

Rajan, R. G., \& Zingales, L. (2000). The governance of the new Enterprise. In X. Vives (Ed.), Corporate governance: theoretical and empirical perspectives (Vol. 6, pp. 201-227). Cambridge: Cambridge University press, chapter.

Rajan, R. G., \& Zingales, L. (2001a). The influence of the financial revolution on the nature of firms. American Economic Review, 91(2), 206-211.

Rajan, R. G., \& Zingales, L. (2001b). The firm as a dedicated hierarchy: a theory of the origins and growth of firms. The Quarterly Journal of Economics, 116(3), 805-851.

Ritala, P., \& Almpanopoulou, A. (2017). In defense of 'eco' in innovation ecosystem. Technovation, 60, 39-42.

Ritter, J. R. (1991). The long-run performance of initial public offerings. The Journal of Finance, 46(1), 3-27.

Roberts, J. (2004). The modern firm. Oxford: Oxford university press.

Roundy, P. T. (2016). Start-up community narratives: the discursive construction of entrepreneurial ecosystems. The Journal of Entrepreneurship, 25(2), 232-248.

Roundy, P. T., Brockman, B. K., \& Bradshaw, M. (2017). The resilience of entrepreneurial ecosystems. Journal of Business Venturing Insights, 8, 99-104.

Roundy, P. T., Bradshaw, M., \& Brockman, B. K. (2018). The emergence of entrepreneurial ecosystems: a complex adaptive systems approach. Journal of Business Research, 86, $1-10$.

Scaringella, L., \& Radziwon, A. (2018). Innovation, entrepreneurial, knowledge, and business ecosystems: old wine in new bottles? Technological Forecasting and Social Change, 136, 59-87.

Schumpeter, J. A. (1934). The theory of economic development. Cambridge: Harvard University Press.

Sedlacek, T. (2011). Economics of good and evil: the quest for economic meaning from Gilgamesh to Wall Street. Oxford: Oxford University Press.

Shane, S. (2003). A general theory of entrepreneurship. Cheltenham: Edward Elgar.

Smith, T. M., \& Smith, R. L. (2015). Elements of ecology. Essex: Pearson Publishers.

Spigel, B. (2017). The relational organization of entrepreneurial ecosystems. Entrepreneurship Theory and Practice, 41(1), 49-72.

Spigel, B., \& Harrison, R. (2018). Toward a process theory of entrepreneurial ecosystems. Strategic Entrepreneurship Journal, 12(1), 151-168. 
Spulber, D. F. (2009). The theory of the firm: microeconomics with endogenous entrepreneurs, firms, markets, and organizations. Cambridge: Cambridge University Press.

Stam, E. (2014). The Dutch entrepreneurial ecosystem, SSRN 2473475. https://ssrn.com/abstract=2473475.

Stam, E. (2015). Entrepreneurial ecosystems and regional policy: a sympathetic critique. European Planning Studies, 23(9), 1759-1769.

Stangler, D., \& Bell-Masterson, J. (2015). Measuring an entrepreneurial ecosystem. Kansas City: Kauffman foundation.

Tansley, A. J. (1935). The use and abuse of vegetational concepts and terms. Ecology, 16, 284-307.

Thompson, T. A., Purdy, J. M., \& Ventresca, M. J. (2018). How entrepreneurial ecosystems take form: evidence from social impact initiatives in Seattle. Strategic Entrepreneurship Journal, 12(1), 96-116.

Tsujimoto, M., Kajikawa, Y., Tomita, J., \& Matsumoto, Y. (2018). A review of the ecosystem concept - towards coherent ecosystem design. Technological Forecasting and Social Change, 136, 49-58.

Venkataraman, S. (1997). The distinctive domain of entrepreneurship research. Advances in entrepreneurship, firm emergence and growth, 3(1), 119-138.

Vernon, R. (1966). International investment and international trade in the product life cycle. Quarterly Journal of Economics, 80, 190-207.

Weinberg, C. R. (2001). Reward strategies for Dot. Corp organizations: Lessons from the front. Compensation and Benefits Review, 33(1), 6-14.

Zingheim, P. K., \& Schuster, J. R. (2000). Total rewards for new and old economy companies. Compensation and Benefits Review, 32(6), 20-23.

Publisher's note Springer Nature remains neutral with regard to jurisdictional claims in published maps and institutional affiliations. 